\title{
O Mercado de Bioaditivos para a Indústria de Alimentos
}

\author{
Lorena O. Felipe \& Juliano L. Bicas
}

O uso de micro-organismos (ou suas enzimas) na elaboração de alimentos ou insumos para a indústria de alimentos ganhou muita importância com o passar dos anos, particularmente, no último século. Dessa maneira, este artigo apresentará os mais importantes bioprocessos de produção de aditivos para a indústria de alimentos, tais como: aminoácidos, ácidos orgânicos, polissacarídeos, vitaminas, antimicrobianos, corantes e aromas. Em todos os casos, serão apresentados dados que mostram a expectativa de crescimento do mercado de cada um desses produtos e, por fim, apresentaremos algumas perspectivas futuras envolvendo as tendências neste setor.

Pala vras-chave: biotecnologia; natural; sustentabilidade.

The use of microorganisms (or their enzymes) in the preparation of food or raw materials for the food industry has gained much importance over the years, particularly in the last century. Thus, this article will present the most important bioprocesses for the production of food/feed additives, such as amino acids, organic acids, polysaccharides, vitamins, antibiotics, colorants and aroma compounds. In all cases, data will be presented showing the expected market growth of each of these products and, finally, we will present some future prospects involving trends in this sector.

Keywords: biotechnology; natural; sustainability. 


\section{Introdução}

A biotecnologia é um termo que remete às mais modernas tecnologias do século XXI, como a engenharia genética e a biologia molecular. Entretanto, essa área da ciência tem seu histórico remontado há mais de 4.000 anos, quando a humanidade passou a produzir alimentos processados clássicos, entre os quais o queijo, a cerveja, o pão e o vinho. Obtidos por vias fermentativas - um dos eixos da biotecnologia - a produção de tais insumos, até o século XIX, foi desenvolvida provavelmente de maneira estritamente apoiada no empirismo. Além disso, baseado tão somente na experiência e na observação, os processos fermentativos também permearam a história da humanidade como estratégia para a conservação de alimentos e na agregação de valor através da melhora da percepção sensorial de diferentes alimentos.

No século XIX, a elucidação dos processos fermentativos adquiriu os primeiros embasamentos teóricos a partir de estudos conduzidos por Louis Pasteur. Posteriormente, já no século XX, a potencialidade e a enorme versatilidade da biotecnologia foram afirmadas com o emprego de biocatalisadores industriais para a produção em larga escala de ácido cítrico (acidulante) e da penicilina (antibiótico).

Atualmente, a biotecnologia desempenha um importante papel na comercialização de produtos ao redor de todo mundo sendo que, no ano de 2014, o mercado global de produtos de origem microbiana foi avaliado em US\$ 143,5 bilhões. Para o período de 2015-2020, esse mesmo mercado tem uma taxa de crescimento projetada em 14,6\% ao ano, com cifras de comercialização avaliadas em US\$ 306 bilhões ${ }^{1}$.

Nesse contexto, não é de surpreender que inúmeros insumos obtidos por via biotecnológica sejam extensamente utilizados por vários nichos industriais, entre os mais importantes: a indústria farmacêutica (vacinas, hormônios, antibióticos), a indústria química (poliésteres, bioinseticidas, glicerol) e a indústria de alimentos (aminoácidos, ácidos orgânicos, antimicrobianos, aromas, corantes, espessantes e vitaminas).

Adicionalmente, fomentado pela recente e vívida discussão a respeito dos benefícios de uma alimentação mais natural, dos alimentos funcionais e nutracêuticos, a biotecnologia tem desempenhado um forte protagonismo na indústria de alimentos, representado majoritariamente pelos bioaditivos alimentares ${ }^{2,3}$. Portanto, o objetivo desse trabalho centra-se na descrição do que há de consolidado na produção de aditivos para a indústria de alimentos, além de fornecer perspectivas futuras para este setor.

\section{Aditivos e Bioaditivos Alimentares: Panorama Geral}

Os aditivos alimentares são compostos adicionados aos alimentos com função de manter, modificar ou realçar alguma característica do produto ao qual foi suplementado. Alguns aditivos são tradicionalmente utilizados desde a antiguidade para a preservação de alimentos, sendo os exemplos mais típicos a utilização do sal, do vinagre e de especiarias.

Impulsionado pela evolução dos hábitos alimentares, os aditivos alimentares apresentam um mercado de milhões de toneladas anuais, equivalente a um mercado de bilhões de dólares. Considerado este fato, as projeções mercadológicas de crescimento global para aditivos e vitaminas no horizonte de cinco anos (2015-2020) são bastante promissoras, como apresentado na Tabela 1 .

Tabela 1. Projeções (2015-2020) globais de mercado de algumas classes de aditivos alimentares e vitaminas ${ }^{4-11}$

\begin{tabular}{|c|c|c|c|}
\hline Setor & US\$ (bilhões) & $\begin{array}{c}\text { Crescimento } \\
\text { anual (\%) }\end{array}$ & $\begin{array}{c}\text { Projeção } \\
\text { (ano) }\end{array}$ \\
\hline $\begin{array}{c}\text { Ácidos } \\
\text { orgânicos }\end{array}$ & 9,29 & 6,00 & 2021 \\
\hline Aminoácidos & 35,40 & 5,60 & 2022 \\
\hline $\begin{array}{c}\text { Aromatizantes } \\
\text { \& saborizantes }\end{array}$ & 33,50 & 5,80 & 2019 \\
\hline Corantes & 2,46 & 4,00 & 2020 \\
\hline Antifúngicos & 1,84 & 3,10 & 2020 \\
\hline $\begin{array}{c}\text { Espessantes } \\
\text { e agentes de } \\
\text { corpo }\end{array}$ & 20,70 & 5,70 & 2020 \\
\hline \begin{tabular}{c} 
Vitaminas \\
\hline
\end{tabular} & 9,30 & 6,15 & 2020 \\
\hline
\end{tabular}


Contudo, o mercado de aditivos alimentares vem passando por uma forte e rápida exigência de adaptação. As novas demandas têm sido fortemente estimuladas por um novo "perfil de consumidores", o qual, de acordo com o "Brazil Ingredients Trends 2020", tem demandado a reformulação de produtos no setor de ingredientes para alimentos com base principalmente em critérios de "naturalidade" e "sustentabilidade"12.

Essa tendência de mercado tem refletido nas práticas de compra: de acordo com uma pesquisa feita pela Markets and Markets, o critério de "naturalidade" no ato da compra de um alimento/bebida tem se mostrado mais crucial do que o preço ou a percepção sensorial. Ainda, $70 \%$ dos consumidores norte-americanos se mostram mais dispostos a pagarem por preços mais elevados na aquisição de produtos que contenham ingredientes naturais em sua fórmula ${ }^{13}$. Outro relatório aponta que $25 \%$ dos consumidores brasileiros reconhecem ser responsabilidade deles dar preferência a produtos que evitem a degradação ambiental. Adicionalmente, 39\% dos brasileiros apresentam uma tendência a adquirirem produtos de marcas que respeitam o meio ambiente ${ }^{14}$.

Nesse contexto, o segmento de aditivos alimentares tem demandado uma rápida substituição por bioaditivos. Esses últimos são caracterizados pela obtenção por via biotecnológica - seja por métodos microbiológicos ou enzimáticos - e consistem em alternativas aos aditivos classicamente produzidos por rotas químicas. Tal processo tecnológico atende aos dois critérios avidamente reivindicados pelo novo mercado consumidor, isto é, os produtos obtidos por essa via são classificados como naturais ${ }^{15}$; além do fato de que são considerados "ambientalmente amigáveis". Essa última característica está associada com os parâmetros de processo comumente empregados na produção por via biotecnológica, os quais geralmente são sintetizados sob temperatura ambiente e pressão atmosférica, impactando também de maneira direta no custo energético da produção ${ }^{16}$.

Os dados do ano de 2015 do mercado global de produtos fermentados reforçam a emergência desse novo negócio: foram comercializadas 56,98 milhões toneladas de produtos obtidos por via fermentativa, sendo que esse volume correspondeu a 44,7\% de toda movimentação de mercado feita nesse mesmo ano. Portanto, um relatório recentemente destaca que o mercado dos produtos fermentados no período de 2016-2024 deverá crescer a 4,6\% ao ano, chegando a US\$ 81,14 bilhões no ano de 2024 , com um volume de comercialização correspondente de 85,66 milhões de toneladas. Dentre as companhias-líder do mercado global de fermentação, vale citar: BASF SE, Amano Enzyme Inc, The Dow Chemical Company, Cargill Inc, Archer Daniels Midland, DuPont Danisco A/S, Ajinomoto Company Incorporation e Evonik Industries ${ }^{17}$. Na sequência, abordaremos os aditivos "biotec" mais comercialmente relevantes.

\section{Aminoácidos}

Os aminoácidos são as unidades monoméricas das proteínas, que são moléculas essenciais para diversas funções fisiológicas nos seres vivos, como função enzimática, de transporte, movimento coordenado, suporte mecânico, entre outros. Em outras palavras, as proteínas - e, consequentemente, os aminoácidos - são essenciais à vida. No entanto, os mamíferos não conseguem sintetizar todos os aminoácidos de que precisam e, assim, alguns deles (chamados "essenciais") devem ser garantidos pela dieta. Este é, na verdade, o princípio nutricional que motiva a produção de alguns dos principais aminoácidos microbianos.

A lisina, por exemplo, é comumente o aminoácido limitante nas rações a base de cereais, ou seja, a baixa quantidade deste aminoácido comumente encontrada em tais produtos limitaria o crescimento e comprometeria a saúde animal. A solução reside na suplementação deste aminoácido. Desse modo, grande parte da lisina obtida industrialmente, destina-se a atender o segmento de suplementação para ração animal. Em 2013, por exemplo, 92,4\% da produção da lisina produzida em escala comercial foi demandada pelo mercado de ração ${ }^{18}$.

Assim sendo, a necessidade da adição da lisina em rações a base de cereais propicia uma regulação no preço desses produtos: a soja, rica em lisina, é misturada ao milho para garantir um balanço adequado de aminoácidos. Porém, quando seu preço aumenta, pode-se substituir a mistura de lisina pela suplementação com lisina (50Kg farelo de soja $\approx 48,5 \mathrm{Kg}$ milho $+1,5 \mathrm{Kg}$ lisina pura). Como o milho tem maior rendimento por hectare, isso também proporciona economia de terra arável. Outras vantagens desta suplementação são a melhora no balanço 
de aminoácidos e na eficiência de aproveitamento de nutrientes, além da redução na quantidade de excremento e de excreção de compostos nitrogenados no ambiente ${ }^{19-21}$.

A produção de lisina por fermentação é comumente feita por cepas de Corynebacterium glutamicum, utilizando: o melaço de cana ou hidrolisado de amido como substrato; amônia, sais de amônio ou ureia como fonte de nitrogênio; homoserina/treonina e metionina como fatores de crescimento; regime de batelada alimentada. Este é um aminoácido produzido a partir do aspartato e compartilha as reações iniciais com as vias de produção de homoserina, metionina, treonina e isoleucina. A primeira dessas reações é catalisada pela enzima aspartato cinase, que sofre retroinibição pelos produtos lisina e treonina. Em outras palavras, os micro-organismos apresentam mecanismos bioquímicos que evitam o acúmulo de aminoácido e, portanto, as linhagens utilizadas na produção de lisina devem ter algumas particularidades: são mutantes auxotróficas para homoserina ou L-treonina, L-metionina e L-isoleucina (o que diminui as vias "competidoras" para a síntese de lisina e reduzem a inibição da aspartato cinase); apresentam uma enzima aspartato cinase resistente à inibição por retroalimentação, além de terem superexpressos os genes envolvidos com a produção e secreção de lisina ${ }^{19-21}$.

No caso da produção da treonina, a lógica empregada é semelhante, tanto em termos de aplicações como em termos de processo. Para sua produção industrial, comumente se utilizam cepas mutantes de Escherichia coli que apresentam como principais características: (i) redução da retroinibição da aspartato cinase e da inibição de sua síntese por treonina; (ii) ausência de genes associados a vias "competidoras" da síntese de treonina (síntese de lisina e metionina com consumo de treonina por degradação ou síntese de isoleucina; (iii) aumento da expressão de genes que formam treonina; (iv) supexpressão dos transportadores que exportam treonina ${ }^{20,21}$.

Outro aminoácido de origem microbiana de grande relevância comercial é o glutamato. Utilizado na forma de sal sódico (glutamato monossódico ou MSG), ele tem grande aplicação na indústria alimentícia como realçador de sabor, atuando como agente de gosto umami. Inicialmente, extraído de algas e posteriormente produzido pela hidrólise do glúten do trigo, a partir da década de 1950 tal aminoácido passou a ser produzido biotecnologicamente pela fermentação microbiana de carboidratos $^{22}$. Atualmente, com um mercado estimado em aproximadamente 2 milhões de toneladas, o glutamato tem sido produzido principalmente por cepas de C. glutamicum $^{23,24}$. As condições operacionais incluem a utilização de melaço de cana, amido hidrolisado, açúcar (cana, beterraba) como meio de cultura, sais de amônio ou ureia como fonte de nitrogênio, temperatura de 30$37^{\circ} \mathrm{C}, \mathrm{pH}$ de $7-8$, além de agitação e aeração (processo aeróbico). Como principais estratégias para acúmulo de glutamato no meio, destacam-se a limitação de biotina, a adição de surfactantes/penicilina ou ainda o uso de cepas auxotróficas para glicerol ou oleato ${ }^{19,21}$.

Além dos aminoácidos citados, outros também podem ser produzidos por fermentação (Tabela 2), mas estes não serão detalhados neste texto, considerando que o foco desse artigo são apenas os aminoácidos de maior relevância comercial.

Tabela 2. Principais vias de obtenção e volume anual de produção de alguns aminoácidos de relevância industrial ${ }^{19}$

\begin{tabular}{|c|c|c|}
\hline Aminoácido & Via de produção1 & $\begin{array}{c}\text { Volume anual de } \\
\text { produção (t) }\end{array}$ \\
\hline L-Alanina & Enz., Ext. & 500 \\
\hline L-Arginina & F & 1,200 \\
\hline L-Asparagina & Ext. & $100-1,000$ \\
\hline L-Ácido aspártico & Enz. & 10,000 \\
\hline L-Cisteína & Enz., Ext. & 3,000 \\
\hline L-Glutamina & F & 1,300 \\
\hline L-Ácido glutâmico & F & $2,930,000$ \\
\hline Glycina & Q & 22,000 \\
\hline L-Histidina & F & 400 \\
\hline L-Isoleucina & F & 400 \\
\hline L-Leucina & F., Ext. & 500 \\
\hline L-Lysina & F & $1,950,000$ \\
\hline DL-Metionina & Q & 750,000 \\
\hline L-Fenilalanina & F, Q & 12,650 \\
\hline L-Prolina & F & 350 \\
\hline L-Serina & F & 350 \\
\hline L-Treonina & F & 330,000 \\
\hline L-Triptofano & Enz., F & 9,000 \\
\hline L-Tirosina & F, Ext. & 165 \\
\hline L-Valina & F & 500 \\
\hline
\end{tabular}


Em termos de mercado, estimativas apontam que no período de 2015-2020 o segmento de aminoácidos deve crescer cerca de 7,3\% ao ano, chegando aos US\$12,6 bilhões em $2020^{25}$. O crescimento deste mercado deverá ser impulsionado principalmente pela região Ásia-Pacífico cuja taxa de crescimento está estimada em 5,1\% ao ano até $2020^{26}$. Como resultado do maior consumo de carne, a região das Américas Central e do Sul também deve ter um incremento acentuado deste mercado, o qual espera-se crescer a $6,5 \%$ ao ano no período de 2015 a 2025, 27. Já o mercado de aminoácidos para aplicações em rações está projetado para crescer a uma taxa maior (5,4\% ao ano), passando de US $\$ 4,4$ bilhões de 2013 para US\$5,7 bilhões em $2018^{28 .}$

O mercado de glutamato monossódico movimentou US $\$ 4,5$ bilhões em 2014, com uma expectativa de movimentação de US\$ 5,85 bilhões em 2020 e uma taxa anual estimada em 4,5\% (2015-2020 ${ }^{29}$. A lisina tem uma taxa anual de crescimento estimada em $6,2 \%$ de 2014-2020, sendo majoritariamente impulsionada pelo mercado de suplementação de ração para suínos. A treonina, por sua vez, tem uma movimentação de mercado estimada em US\$ 420 milhões $^{30}$.

\section{Ácidos Orgânicos}

Os acidulantes são aquelas substâncias que quando adicionadas aos alimentos têm a função de aumentar a acidez ou atribuir a determinado produto gosto ácido. Contudo, a adição de ácidos orgânicos e seus sais aos alimentos apresenta efeitos que vão além da acidez e do gosto: alguns apresentam ação quelante, atuam como antioxidantes e previnem oxidação lipídica, contribuem com a estabilidade microbiológica, inibem escurecimento enzimático, estabilizam produtos lácteos, entre outros ${ }^{20}$,

${ }^{31}$. Dessa forma, a produção em escala industrial de ácidos orgânicos é prioritariamente voltada para atender ao setor de ingredientes de alimentos e bebidas ${ }^{32}$.

Não surpreendentemente, o nicho regional que apresenta maior demanda da produção em escala comercial de ácidos orgânicos é o eixo Ásia-Pacífico. Por outro lado, considerando a emergência do novo perfil consumidor, como já discutido nesse texto, principalmente nos continentes Norte-Americano e Europeu, o fator-chave de crescimento do mercado de acidulantes nesses continentes está sendo fortemente dirigido pela produção de ácidos orgânicos por via biotecnológica ("bioacidulantes") 33 .
Dentre todos os ácidos orgânicos empregados em alimentos, oácido cítrico e oácido lático são majoritariamente obtidos por processos fermentativos cujos detalhes serão apresentados na sequência ${ }^{20}$. Embora o ácido acético esteja presente em uma série de produtos fermentados, a maior parte do seu grande mercado (indústria química) tem origem no produto sintetizado quimicamente. Portanto, tal ácido não será detalhado neste texto. A produção anual de ácido cítrico é estimada em cerca de 1.750 .000 toneladas. Em 2015, os mercados norte-americano, asiático e europeu foram responsáveis pelo consumo de $23 \%$, 28\% e $22 \%$ de toda produção mundial de ácido cítrico, respectivamente ${ }^{34}$. Ainda, motivado principalmente pelo aumento dos ácidos de origem natural, o mercado de ácido cítrico deverá crescer a 5,5\% no período de 2015-2020. Desse modo, espera-se que o mercado global desse acidulante passe de US\$ 2,6 bilhões em 2014 para US\$ 3,6 bilhões em $2020^{32 .}$

No que diz respeito ao bioprocesso de produção, cepas bacterianas de Arthrobacter e Actinomyces; leveduras como Candida spp. e Yarrowia lipolytica, bem com linhagens fúngicas de Trichoderma, Penicillium, Mucor e Aspergillus podem ser utilizadas para a obtenção de ácido cítrico "biotec". Todavia, o biocatalisador mais utilizado é o Aspergillus niger. A preferência por essa linhagem está associada à sua capacidade de acumular altas concentrações do referido acidulante ${ }^{35,36}$.

Basicamente, o processo fermentativo empregando A. niger ocorre a partir da fermentação submersa de meio contendo alta concentração de carboidrato e oxigênio dissolvido; quantidades limitantes de íons metálicos (ferro e manganês) e fosfato; pH ajustado abaixo de 7 e agitação contínua. O barateamento do substrato de cultivo pode ser viabilizado através do emprego de melaço de cana após tratamento prévio para remoção por precipitação de íons metálicos. A biossíntese de ácido cítrico ocorre pela ação da enzima citrato sintase a partir da catálise de dois intermediários da primeira etapa do Ciclo de Krebs - o ácido oxaloacético e da acetil-CoA. Mais recentemente, na tentativa de reduzir o custo da produção de ácido cítrico "biotec", a fermentação em estado sólido tem sido extensamente investigada. Isso porque, resíduos agroindustriais de baixo custo - como, por exemplo, farelo de soja/trigo e cascas de maçã/mandioca - podem ter seu valor agregado empregando para a bioconversão de ácido cítrico por A. niger ou Y. lipolytica ${ }^{20,36}$. 
O ácido lático tem seu nome derivado da fonte da qual foi inicialmente isolado por Carl Wilhelm Scheele, isto é, do leite coalhado. Industrialmente, cerca de $90 \%$ de todo o ácido lático produzido no mundo é proveniente de fermentações bacterianas e os outros $10 \%$ são produzidos sinteticamente ${ }^{37}$. O bioprocesso de obtenção do ácido lático utiliza-se de bactérias láticas, particularmente Lactobacillus delbrueckii subsp. delbrueckii, bulgaricus ou lactis, que embora sejam muito exigentes nutricionalmente, são capazes de acumular grandes quantidades deste ácido pela fermentação de carboidratos ${ }^{38}$.

Em 2015, o mercado de maior demanda de ácido lático foi o continente Europeu seguido do Norte Americano $^{39}$. Considerando que este produto é o ponto de partida para a produção de poli(ácido lático) (PLA), um tipo de plástico biodegradável que pode ser utilizado em embalagens de produtos que seguem normas ambientais, tem sido observada uma crescente demanda por este ácido $^{40}$. Assim, as projeções do mercado de ácido lático são bastante promissoras: com uma taxa de crescimento anual de $18,6 \%$ entre 2014 e 2020 , seu mercado deve atingir US\$ 4,3 bilhões ao final deste período ${ }^{40,41}$.

\section{Polissacarídeos}

Os polissacarídeos encontram vasta aplicação industrial e comercial. Dentre os setores de maior consumo de polissacarídeos, está a indústria de alimentos. Desse modo, no setor de ingredientes para alimentos, esses aditivos são empregados para a obtenção de vários efeitos desejados, entre os quais: agentes formadores de filmes, controladores de cristalização, espessantes, estabilizantes, geleificantes, inibidores de sinérese e texturizantes. Outras propriedades que são comuns a todos os polissacarídeos e que tornam esses produtos bastantes versáteis para o uso em alimentos são: a atoxidade, a biocompatilidade, a biodegradabilidade e a polifuncionalidade ${ }^{42}$. Considerada a enorme versatilidade desse segmento de mercado, a previsão para o período de 2015 a 2020 é de um crescimento anual de 5,7\%, atingindo um mercado estimado em US\$20,7 bilhões em $2020^{\circ}$.

Os polissacarídeos obtidos por via biotecnológica são denominados de exopolissacarídeos (EPS) (Tabela 3). Tais moléculas recebem essa denominação por serem polissacarídeos extracelulares, que se constituem de produtos excretados durante o processo fermentativo no substrato de cultivo. Os fungos e as bactérias se constituem como os principais micro-organismos empregados nos bioprocessos para a produção de EPS. Dentre os EPS obtidos de origem microbiana, as gomas se destacam em função de duas propriedades reológicas principais: a tixotropia e a pseudoplastia ${ }^{42-44}$.

Tabela 3. Exopolissacarídeos obtidos por via biotecnológica, propriedades funcionais e micro-organismos produtores $^{42}$

\begin{tabular}{|c|c|c|}
\hline EPS & Propriedade funcional & $\begin{array}{l}\text { Micro-organismo } \\
\text { produtor }\end{array}$ \\
\hline \multirow{5}{*}{$\beta$-glucana } & \multirow{5}{*}{$\begin{array}{l}\text { Espessante, estabilizador, } \\
\text { geleificante, texturizador. }\end{array}$} & Alternaria solani \\
\hline & & Aspergillus nidulans \\
\hline & & $\begin{array}{c}\text { Aureobasidium } \\
\text { pullulans }\end{array}$ \\
\hline & & Botrytis cinerea \\
\hline & & $\begin{array}{l}\text { Paecylomyces } \\
\text { lilacinus }\end{array}$ \\
\hline \multirow{3}{*}{ Alginato } & \multirow{3}{*}{$\begin{array}{l}\text { Apresenta função geleificante } \\
\text { quando adicionado junto ao } \\
\text { cálcio. Forma suporte para } \\
\text { a imobilização de enzimas e } \\
\text { células. }\end{array}$} & Lactobacillus spp. \\
\hline & & Leuconostoc spp. \\
\hline & & Bifidobacterium spp. \\
\hline Celulose & $\begin{array}{c}\text { Espessante. Quando } \\
\text { associado na presença de } \\
\text { outro hidrocoloides é capaz } \\
\text { de potencializar a viscosidade } \\
\text { do meio. }\end{array}$ & Acetobacter xylinum \\
\hline Pululana & Estabilizador e espessante. & $\begin{array}{l}\text { Aureobasidium } \\
\text { pullulans }\end{array}$ \\
\hline \multirow{2}{*}{$\begin{array}{l}\text { Goma } \\
\text { curdulana }\end{array}$} & \multirow{2}{*}{$\begin{array}{l}\text { Empregado como suporte } \\
\text { para a imobilização de } \\
\text { enzimas. }\end{array}$} & $\begin{array}{c}\text { Alcaligenes faecalis } \\
\text { var. myxogene }\end{array}$ \\
\hline & & $\begin{array}{l}\text { Agrobacterium } \\
\text { radiobacter }\end{array}$ \\
\hline $\begin{array}{l}\text { Goma } \\
\text { gelana }\end{array}$ & $\begin{array}{l}\text { Apresenta estabilidade em } \\
\text { uma extensa faixa de pH. } \\
\text { Empregada na produção } \\
\text { de géis termorreversíveis. } \\
\text { Tem potencialidade para } \\
\text { a substituição de alguns } \\
\text { polissacarídeos, como: ágar, } \\
\text { pectina e } \kappa \text {-carragena. }\end{array}$ & Pseudomonas elodea \\
\hline \multirow{2}{*}{$\begin{array}{l}\text { Goma } \\
\text { levana }\end{array}$} & \multirow{2}{*}{$\begin{array}{l}\text { Estabilizar, emulsificante, } \\
\text { agente formador de filmes. }\end{array}$} & Zymomonas mobilis \\
\hline & & Bacillus subtilis \\
\hline \multirow{6}{*}{$\begin{array}{c}\text { Goma } \\
\text { xantana }\end{array}$} & \multirow{6}{*}{$\begin{array}{l}\text { Empregada na produção } \\
\text { de géis termorreversíveis. } \\
\text { Agente formador de filmes. } \\
\text { Potencializa a viscosidade } \\
\text { do meio quando da presença } \\
\text { de outros hidrocoloides. } \\
\text { Estabilizador, geleificante, } \\
\text { texturizador e espessante. }\end{array}$} & $\begin{array}{l}\text { Xanthomonas } \\
\text { campestris }\end{array}$ \\
\hline & & X. fragaria \\
\hline & & $\mathrm{X}$. gummisudans \\
\hline & & $\mathrm{X}$. juglandis \\
\hline & & X. phaseoli \\
\hline & & X. vasculorum \\
\hline
\end{tabular}


Dentre os EPS obtidos por via biotecnológica, a goma xantana se destaca como o bioproduto de maior importância comercial. A xantana se constitui de um heteropolissacarídeo estruturado pelo agrupamento sucessivo de resíduos dos monossacarídeos glicose, manose e ácido glucurônico, na proporção de 2:2:1, respectivamente. $\mathrm{O}$ interesse comercial por essa goma, principalmente, na indústria de alimentos, está associado a suas propriedades, tais como: (i) estabilidade em ampla faixa de temperatura e $\mathrm{pH}$; (ii) grande aumento na viscosidade mesmo em baixas concentrações; (iii) sinergia (guar, Jataí) e possibilidade de formar gel com outras gomas (Jataí); (iv) propriedades pseudoplásticas, ou seja, sua viscosidade é reduzida com o aumento da tensão de cisalhamento (desejável para aplicação em caldas e molhos) ${ }^{44}$. A xantana é produzida comercialmente pela bactéria Gram-negativa Xanthomonas campestris, por meio de um bioprocesso que costuma empregar fermentação submersa aeróbica de carboidratos (glicose, scarose) a um $\mathrm{pH}$ próximo da neutralidade e temperatura de cerca de $28^{\circ} \mathrm{C}$. Nessas condições, pode-se obter de 20 a $30 \mathrm{~g} / \mathrm{L}$ de produto ${ }^{42,44}$.

Em se tratando dos dados de mercado da goma xantana, a estimativa é que, em 2020, a cifra de comercialização atinja US\$ 987,7 milhões. No ano de 2013, 80\% do volume produzido de goma xantana destinou-se a atender a indústria alimentícia e de extração de petróleo. O eixo Ásia-Pacífico foi responsável pela absorção de $40 \%$ da quantidade de goma xantana produzida mundialmente. Os principais players produtores de xantana são: Fufeng Group, Deosen Biochemical Ltd, CP Kelco, ADM, Jungbunzlauer, DuPont Danisco, Meihua Group and Pfizer Inc. ${ }^{45}$.

A despeito das aplicações tradicionais dos EPS's, tais como anteriormente descritos, outras aplicações para esse grupo de biomoléculas têm se estendido para demais áreas. Por exemplo, a existência de grupos carregados na superfície desses bioprodutos podem ser empregados para a biorremediação de metais pesados em determinados efluentes. Adicionalmente, os EPS's também apresentam potencial de uso na área farmacêutica ${ }^{46}$. Em se tratando dessa última aplicabilidade, a recente aquisição da Hospira pela Pfizer Inc. foi motivada principalmente pelo forte interesse em aumentar a produção da goma xantana para fins biomédicos ${ }^{47}$. Desse modo, este cenário demonstra que os EPS microbianos deverão ter uma importância crescente em aplicações não alimentares nos próximos anos.

\section{Vitaminas}

As vitaminas se constituem de um grupo de moléculas orgânicas de diferentes classes químicas. Estes nutrientes mostram-se essenciais para a manutenção do metabolismo de muitos seres vivos e, como tais organismos não são capazes de sintetizá-las, estas vitaminas devem ser fornecidas pela dieta. A deficiência de vitaminas pode levar ao acometimento de doenças, entre as quais, a beribéri, o escorbuto e a anemia. Considerado isso, a adição de vitaminas nos gêneros alimentícios tem por objetivo reforçar o valor nutricional dos gêneros alimentícios, sendo essa suplementação reconhecida como enriquecimento/fortificação ${ }^{48}$.

O mercado da produção de vitaminas tem sido fortemente estimulado pelo crescente aumento da demanda de diferentes nichos, a citar: alimentos funcionais/nutracêuticos ${ }^{49}$, nutrição esportiva e de ração animal. Em função disso, o crescimento anual deste mercado para o período de 20132018 é estimado em $6,15 \%$ e outras estimativas apontam que em 2020 esse mercado atinja a cifra de US\$ 9,3 bilhões. Os principais players do mercado global de vitaminas são: Adisseo France S.A.S, Archer Daniels Midland Co., BASF SE, e Royal DSM N.V.10, ${ }^{50}$.

Dentre as vitaminas apresentadas na Tabela 4, a vitamina B2 (riboflavina) e a B12 (cobalamina) são aquelas obtidas exclusivamente por via biotecnológica $\mathrm{e}$ serão detalhadas no texto.

Tabela 4. Produção de vitaminas: rota, quantidade e usos ${ }^{51,52}$

\begin{tabular}{|c|c|c|c|}
\hline Vitamina & $\begin{array}{c}\text { Via de } \\
\text { produção }^{1}\end{array}$ & $\begin{array}{c}\text { Produção } \\
\text { mundial }^{2} \\
\text { (t/ano) }\end{array}$ & $\begin{array}{c}\text { Principal } \\
\text { aplicação } \\
\text { industrial3 }\end{array}$ \\
\hline A (Retinol) & Q, Ext. & $2.700 \mathrm{~b}$ & $\mathrm{R}, \mathrm{A}, \mathrm{F}$ \\
\hline B1 (Tiamina) & Q & $3.700 \mathrm{~b}$ & $\mathrm{~A}, \mathrm{~F}$ \\
\hline B2 (Riboflavina) & Bio & $4.400 \mathrm{c}$ & $\mathrm{R}, \mathrm{F}$ \\
\hline B3 (Niacina) & Bio, Q & $40.000 \mathrm{c}$ & $\mathrm{R}, \mathrm{A}, \mathrm{F}$ \\
\hline $\begin{array}{c}\text { B5 (Ácido } \\
\text { pantotênico) }\end{array}$ & Bio5, Q & $7.000 \mathrm{a}$ & $\mathrm{R}, \mathrm{A}, \mathrm{F}$ \\
\hline B6 (Piridoxina) & Q & $3.800 \mathrm{~b}$ & $\mathrm{R}, \mathrm{A}, \mathrm{F}$ \\
\hline B7 (Biotina) & Bio5, Q & $112 \mathrm{c}$ & $\mathrm{R}, \mathrm{F}$ \\
\hline B9 (Ácido fólico) & Q & $534 b$ & $\mathrm{R}, \mathrm{A}, \mathrm{F}$ \\
\hline B12 (Cobalamina) & Bio & $175 c$ & $\mathrm{R}, \mathrm{A}, \mathrm{F}$ \\
\hline C (Ácido ascórbico) & Bio4, Q & $10.700 \mathrm{~b}$ & $\mathrm{R}, \mathrm{A}, \mathrm{F}$ \\
\hline E (Tocoferol) & Bio4, Q, Ext & $30.000 \mathrm{~b}$ & $\mathrm{R}, \mathrm{A}, \mathrm{F}$ \\
\hline
\end{tabular}

${ }^{1}$ Via principal - Bio: Biotecnológico; Q: Química; Ext.: Extração. ${ }^{2}$ Ano-base: a1990s; b2000s; c2010. ${ }^{3}$ Principais aplicações: A: alimentos; F: farmacêutica; R: rações. ${ }^{4}$ Biotransformações. ${ }^{5}$ Escala piloto. 
A riboflavina é uma vitamina de coloração amarelada, mas cujo uso como corante é limitado devido ao odor indesejado e gosto amargo. Ela pode ser produzida por síntese química ou por fermentação, sendo que esta é a principal modalidade de produção: entre 1990 e 2002, a fatia de riboflavina proveniente de bioprocessos passou de $5 \%$ para $75 \%$. Atualmente, existem dois sistemas de produção desta vitamina, um empregando o fungo Ashbya gossypii (BASF) e outro a bactéria Bacillus subtilis (DSM e Hubei Guangji), ambos resultados de melhoramento clássico de linhagens, engenharia genética e otimização de processos. No ano de 2010, a produção total desta vitamina foi de aproximadamente 4,4 mil toneladas, sendo que 70 a $75 \%$ delas foram destinadas para aplicações em ração e o restante foi destinado para produtos farmacêuticos e alimentos ${ }^{51-53}$.

A vitamina B12 é a mais complexa das vitaminas, de forma que sua produção industrial por síntese química, que requer mais de 70 passos, nunca foi feita. Por este motivo, ela é fabricada exclusivamente por fermentação cujo processo principal envolve uma via anaeróbica de Pseudomonas denitrificans. Pode-se obter uma concentração de dezenas de $\mathrm{mg} / \mathrm{L}$ utilizando como fonte de carbono melaço de beterraba açucareira, que contém betaína (efeito estimulatório) e adição de sais de cobalto. Como a vitamina B12 é encontrada somente em tecidos animais e micro-organismos e, por este motivo, pessoas vegetarianas estão sujeitas a sofrer com sua deficiência. Assim, o principal uso desta vitamina é como suplemento nutricional. Apesar de sua produção anual ser baixa, cerca de $3 \mathrm{t}$, este é um produto de elevado valor agregado (milhares de euros $/ \mathrm{kg})^{53}$.

\section{Agentes Antimicrobianos}

Os agentes antimicrobianos são substâncias que quando adicionadas aos alimentos são capazes de inibir ou inativar micro-organismos patogênicos ou deterioradores. Os aditivos antimicrobianos apresentam uma extensa diversidade química (ácidos orgânicos, proteicos, polipeptídios) e, consequentemente, demonstram uma vasta aplicabilidade. Os óleos essenciais, que também abarcam uma enorme variedade de classes químicas, destacam-se como compostos antimicrobianos que têm sido utilizados pela humanidade desde a antiguidade ${ }^{54}$.
A nisina e a natamicina pertencem ao grupo de compostos antimicrobianos que podem ser obtidos por via biotecnológica. O bioprocesso empregado para a produção da nisina se constitui na fermentação submersa do soro de leite/leite por cepas de Lactococcus lactis subespécie lactis, uma bactéria Gram-positiva pertencente ao grupo das bactérias ácido-láticas. Por outro lado, a obtenção de natamicina é feita a partir de linhagens de Streptomyces natalensis - um actinomiceto ${ }^{55,56}$.

Enquanto a natamicina é um representante dos antifúngicos macrolídeos poliênnicos, a nisina pertence ao grupo dos polipeptídios antimicrobianos reconhecidos como bacteriocinas - que são metabólitos primários que tem sua biossíntese feita em nível ribossomal. O espectro de ação das bacteriocinas é reconhecidamente estreito, sendo assim, linhagens produtoras de bacteriocinas só são capazes de inibir ou matar aquelas bactérias que apresentam íntima relação parental com elas mesmas $(\text { Tabela 5) })^{55,56}$.

A nisina é empregada para a conservação de alimentos em mais de 50 países ao redor de todo o mundo e foi a primeira bacteriocina a receber o status GRAS (nomenclatura dada à substâncias reconhecidas como seguras) $)^{54,55}$.A nisina, quando adicionada ao alimento, não promove alteração da percepção sensorial além de auxiliar na extensão do tempo de prateleira dos produtos. Dessa maneira, a nisina se mostra efetiva contra linhagens de micro-organismos produtores de esporos termorresistentes como Clostridium e Bacillus. Considerado isso, é possível aumentar o prolongamento da vida de prateleira, associado a tratamentos térmicos mais brandos, impactando, assim, no custo energético de produção. Outro aspecto atrativo do uso da nisina em alimentos está no fato de que esse agente antimicrobiano pode ser utilizado em produtos fermentados por leveduras, mantendo-as viáveis durante o processo fermentativo. Isso porque, em função da complexidade da parede celular desses micro-organismos, a nisina não apresenta atividade antimicrobiana contra leveduras, bolores e bactérias Gram-negativas. Por outro lado, a nisina apresenta amplo espectro de ação contra microorganismos Gram-positivos, sendo o representante mais importante a Lysteria monocytogenes - um importante micro-organismo causador de Doenças Transmitidas por Alimentos $^{54,55}$. 
No Brasil, que autoriza a aplicação de nisina apenas em queijos pasteurizados em uma quantidade de $12,5 \mathrm{mg} /$ $\mathrm{Kg}$, a demanda por esse conservante está estimada em cerca de $800 \mathrm{Kg} /$ ano. Para uso industrial, a nisina possui um valor de US\$ 900/Kg, sendo que a nisina pura custa cerca de US\$ 30,8/g $\mathrm{g}^{54}$.

Anatamicina, inicialmente denominada de pimaricina, é utilizada na indústria de alimentos como agente antimicrobiano para prevenir a proliferação de fungos (Tabela 5), não apresentado efetividade contra vírus ou bactérias. Assim sendo, a natamicina pode ser empregada como agente antimicrobiano em fermentações conduzidas por bactérias, inibindo a proliferação de fungos sem causar prejuízos para a maturação ou o processo fermentativo do produto. Outro aspecto relevante do uso da natamicina em alimentos centra-se no fato de que em doses abaixo das doses de inibição - as chamadas concentrações subinibitórias - esse conservante é capaz de prevenir a produção de micotoxinas. Essas últimas, substâncias de elevado caráter tóxico produzido como metabólitos secundários por diferentes fungos. A toxidez apresentada por micotoxinas, dependendo da dose ingerida, vai desde o acometimento de estados de letargia, por exemplo, ao

Tabela 5. Espectro de ação da nisina e da natamicina ${ }^{54}$

\begin{tabular}{|c|c|}
\hline Nisina & Natamicina \\
\hline \multicolumn{2}{|c|}{ Micro-organismo-alvo } \\
\hline $\begin{array}{l}\text { Alicyclobacillus } \\
\text { acidoterrestris }\end{array}$ & Absidia sp. \\
\hline Bacillus brevis & Alternaria sp. \\
\hline Bacillus cereus & Aspergillus chevalieri \\
\hline Bacillus subtilis & Aspergillus flavus \\
\hline Bacillus stearothermophilus & Aspergillus niger \\
\hline Clostridium bifermentans & Aspergillus oryzae \\
\hline Clostridium botulinum & Botrytis cinerea \\
\hline Listeria monocytogenes & Byssochlamys fulva \\
\hline \multirow[t]{8}{*}{ Staphylococcus aureus } & Cladosporium cladosporioides \\
\hline & Fusarium solani \\
\hline & Gloeosporium album \\
\hline & Mucor mucedo \\
\hline & Penicillium candidum \\
\hline & Penicillium chrysogenum \\
\hline & Penicillium digitatum \\
\hline & Sclerotinia fructicola \\
\hline
\end{tabular}

óbito de animais/seres humanos ${ }^{54,56,57}$.

A seletividade da natamicina por fungos é explicada pela capacidade que essa molécula apresenta de formar uma ligação irreversível com o ergosterol - o componente mais importante da parede celular da parede fúngica. A irreversibilidade da ligação provoca a morte celular pela alteração da permeabilidade membranar e, por conseguinte, o extravasamento do conteúdo celular ${ }^{54,56}$.

$\mathrm{O}$ mercado de agentes antimicrobianos inibidores de fungos, como a natamicina, por exemplo, apresenta um crescimento estimado de $3,1 \%$ ao ano, com uma cifra de comercialização estimada em US\$ 1,84 bilhões para o ano de $2020^{8}$. Boa parte deste crescimento resulta da demanda apresentada pelo mercado de rações, seja para rebanhos confinados, pet's e aquacultura. Tais nichos aumentarão consideravelmente a demanda por agentes controladores de micro-organismos fúngicos considerada a conscientização acerca da toxidez das micotoxinas e as nefastas consequências desse grupo de substâncias químicas em matérias-primas utilizadas para a produção de ração $0^{58}$.

\section{Corantes}

Micro-organismos produtores de pigmentos são relativamente comuns. Carotenoides, melaninas, flavinas, quininas e, mais especificamente monascinas, violaceínas, ficocianinas ou índigo estão entre as moléculas coloridas capazes de serem produzidas ${ }^{59}$. Existem vários relatos de processos de produção de corantes por fungos, bactérias e microalgas descritos na literatura ${ }^{60,61} \mathrm{e}$ alguns já patenteados. A maioria desses trabalhos publicados se referem à produção de corantes amarelo-alaranjados e vermelhos, como aqueles derivados dos fungos dos gêneros Monascus, Penicillium e Fusarium. Ademais, microalgas têm sido extensamente estudadas e são atualmente empregadas na produção comercial dos chamados "biopigmentos", especialmente carotenoides e ficolibiproteínas ${ }^{62,63}$.

Os carotenoides (astaxantina, licopeno, zeaxantina e $\beta$-caroteno) constituem a principal classe de pigmentos naturais e atraem muito o interesse da indústria de alimentos e bebidas por representarem uma fonte (potencialmente natural) de corantes com cor variando do amarelo ao vermelho ${ }^{64}$. Estes compostos podem ser produzidos em escala comercial por micro-organismos, 
especialmente microalgas.

Espécies do gênero Dunaliella, uma microalga halotolerante unicelular que cresce em altas concentrações salinas, pode acumular grandes quantidades (3-5\%, até $14 \%$ ) de $\beta$-caroteno ${ }^{62}$. Tal fato torna estes microorganismos os principais produtores de carotenoids ( $\beta$-caroteno), sendo as espécies $D$. salina e $D$. bardawil as mais comumente cultivadas. Assim, muitas companhias estão envolvidas no cultivo de Dunaliella para produção comercial deste caroteno, que encontra aplicações em alimentos, rações e formulações farmacêuticas ${ }^{59}$. Há ainda um outro processo de produção, iniciado em 1995 na Europa (DSM), que envolve o fungo Blakeslea trispora, o qual pode acumular $4 \%$ ou mais do seu peso como $\beta$-caroteno.

O mercado de $\beta$-caroteno corresponde a cerca de $20 \%$ do mercado total de carotenoides. Seu mercado deve passar de US\$261 milhões em 2010 para US\$334 milhões em 2018, com um crescimento anual de 3,1\% Do total produzido, cerca de $15 \%$ tem origem microbiana, produto este cujo preço pode variar de US\$300-3.000/Kg ante cerca de US\$1.000 para o produto sintético ${ }^{53}$.

A astaxantina é outro carotenoide de origem microbiana com importância comercial. Este é o pigmento associado à coloração avermelhada em salmão, crustáceos e outros animais. A maior parte da astaxantina é produzida quimicamente, sendo uma parcela menor oriunda de crustáceos. Apenas uma pequena fatia, estimada em menos de $10 \%$ do total, é produzida por micro-organismos ${ }^{53}$. O mercado de astaxantina, que no ano de 2010 foi estimado em US\$226 milhões, deve crescer a $1,4 \%$ ao ano e chegar a US\$253 milhões em $2018^{65}$. Sua principal aplicação é em ração para aquacultura, na criação de salmão e truta.

O principal processo de produção biotecnológica de astaxantina envolve microalgas de água doce da espécie Haematococcus pluvialis, que podem acumular de 1,5 a 3\% deste carotenoide. Este bioprocesso envolve duas etapas: o "estágio verde", de crescimento celular, seguido pelo "estágio vermelho", de acúmulo de astaxantina, quando são aplicadas condições de estresse (elevada intensidade luminosa e meio pobre em nutrientes) para induzir a produção. Embora existam algumas companhias produzindo astaxantina microbiana, esta ainda não consegue competir em termos de preço com o produto sintético ${ }^{53}$.
Já a produção de corantes azuis por micro-organismos é raramente relatada para fungos ou bactérias ${ }^{66,67}$, mas é mais comum para microalgas. Além da clorofila e carotenoides, muitos micro-organismos fotossintetizantes produzem pigmentos acessórios chamados ficoeritrinas (vermelhos) e ficocianinas (azuis), que são coletivamente conhecidos como ficolibiproteínas ${ }^{59}$. Além das aplicações como corantes naturais em alimentos e cosméticos, tais compostos podem ser utilizados em aplicações clínicas ou em pesquisas imunológicas. Além disso, um crescente número de pesquisadores tem relatado suas propriedades benéficas à saúde e uma grande variedade de aplicações farmacêuticas têm sido consideradas ${ }^{68}$.

Para se ter uma ideia do mercado de ficolibiproteínas, em 1997 este foi estimado em US\$50 milhões, com preços variando de US\$3-25/mg para os pigmentos nativos ${ }^{68}$. Em escala comercial, a cianobactéria Arthrospira e a rodofícea Porphyridium são as principais microalgas utilizadas para a produção de ficocianinas e ficoeritrinas, respectivamente ${ }^{59}$.

\section{Aromas}

No setor de ingredientes para alimentos e bebidas, os aromatizantes são empregados para agregar valor ao produto, por meio da melhora e do reforço da percepção sensorial. Portanto, a adição de tais substâncias é crucial na aceitação do consumidor, implicando diretamente no sucesso de comercialização de determinado alimento. Entretanto, a adição de compostos de aroma em bebidas, por exemplo, pode impactar em até $50 \%$ no custo da formulação ${ }^{69}$. Dentre as características apresentadas pelos compostos de aromas, destacam-se: volatilidade acentuada, moléculas de tamanho igual ou inferior a 300 Daltons, apresentam a habilidade de ativarem os receptores olfativos ${ }^{70}$.

Os compostos de aroma adicionados aos alimentos podem ser rotulados como "naturais", no caso de compostos de origem microbiana/enzimática ou extração direta da natureza; "idênticos ao natural", no caso de serem sintetizados quimicamente mas apresentarem estrutura química idêntica a um composto encontrado na natureza; ou "artificial", no caso de moléculas sintetizados quimicamente e não encontradas na natureza ${ }^{69}$. Os referidos métodos de obtenção apresentam vantagens e desvantagens, como as destacadas na Tabela 6 . 
Tabela 6 - Vantagens e desvantagens dos métodos de obtenção dos compostos de aroma ${ }^{69}$

\begin{tabular}{|c|c|c|}
\hline Método & Vantagem & Desvantagem \\
\hline $\begin{array}{c}\text { Extração direta da } \\
\text { natureza }\end{array}$ & $\begin{array}{c}\text { Ótima qualidade } \\
\text { sensorial, produtos } \\
\text { naturais }\end{array}$ & $\begin{array}{c}\text { Alto custo, } \\
\text { influência da } \\
\text { sazonalidade }\end{array}$ \\
\hline Síntese química & $\begin{array}{c}\text { Alto rendimento e } \\
\text { baixo custo }\end{array}$ & $\begin{array}{c}\text { Baixa seletividade, } \\
\text { possível impacto } \\
\text { ambiental }\end{array}$ \\
\hline Via biotecnológica & $\begin{array}{c}\text { Maior seletividade, } \\
\text { condições brandas } \\
\text { de operação, } \\
\text { resíduos não } \\
\text { tóxicos. }\end{array}$ & $\begin{array}{c}\text { Alto custo e } \\
\text { dificuldade no } \\
\text { escalonamento do } \\
\text { processo }\end{array}$ \\
\hline
\end{tabular}

Desse modo, considerando o forte impacto da biotecnologia no segmento de química fina $a^{71}$, mercado de bioaromas vem apresentando crescimento considerável nas últimas décadas. Adicionalmente, com a maior demanda por aromas naturais cujo mercado está crescendo a uma taxa estimada de $9,1 \%$ ao ano ${ }^{72}$, projetase que o papel dos aromas "biotec" deve apresentar um papel crescente na indústria de alimentos.

Em se tratando de aromas "biotec" já disponíveis, a vanilina (4-hidróxi-3-metoxibenzaldeído) e a gamadecalactona (ácido 4-hidroxi-decanóico) apresentamse como as substâncias com as maiores demandas, com produções da ordem de milhares de toneladas. Por exemplo, no ano de 2010, o volume de produção da vanilina foi igual a 15.000 toneladas $^{73}$. A vanilina é responsável pelo aroma de baunilha, enquanto a gamadecalactona tem aroma de pêssego. Ambas as substâncias possuem métodos de obtenção por via biotecnológica já consolidados a nível industrial. Enquanto a vanilina pode ser obtida por diferentes processos (Tabela 7), a gamadecalactona costuma ser produzida pela biotransformação do ácido ricinoleico (encontrado no óleo de mamona) pela levedura Yarrowia lipolytica. E, quando comparados os valores de comercialização em função da rota de obtenção, tanto a vanilina quanto a gama-decalactona apresentam valores bastante competitivos: vanilina (natural: US\$ 1.200 à 4.000; "biotec": US\$ 1.000; sintética: US\$ 15); gama-decalactona (natural: US\$ 6.000; "biotec": US\$ 300; sintética: US\$ 150 $)^{73-75}$.
Tabela 7 - Companhias responsáveis pela produção de vanilina "biotec" "?

\begin{tabular}{|c|c|c|}
\hline Companhia & Matéria-prima & $\begin{array}{c}\text { Substrato de } \\
\text { conversão }\end{array}$ \\
\hline $\begin{array}{c}\text { De Monch } \\
\text { Aromatics }\end{array}$ & Cúrcuma & Curcumina \\
\hline Evolva/IFF & Milho & Glicose \\
\hline Mane & Cravo & Eugenol \\
\hline Solvay & Farelo de arroz & Ácido ferrúlico \\
\hline
\end{tabular}

Em se tratando da expectativa global de mercado, espera-se que o mercado de vanilina cresça a uma taxa entre 7 e $10 \%$ ao ano entre 2016 a 2025, sendo que essa taxa será pressionada pela alta demanda do setor de ingredientes voltado para a confeitaria e panificação ${ }^{76}$.

\section{Perspectivas Futuras}

$\mathrm{O}$ modo de vida humano na sociedade moderna tem se mostrado cada vez mais como um grande desafio à preservação do meio ambiente, o que vem forçando a conscientização da sociedade e promovendo um intenso debate envolvendo o conceito de sustentabilidade. Paralelamente, há uma crescente demanda por ingredientes e aditivos naturais a serem empregados na formulação de produtos industriais. Nesse contexto, processos biotecnológicos têm surgido como uma alternativa atrativa ao extrativismo e aos processos de síntese química, uma vez que eles geram produtos considerados naturais, são provenientes de fontes renováveis e virtualmente inextinguíveis, além de não gerarem resíduos tóxicos. Tal fato tem provocado, nos últimos anos, uma intensa corrida científica por materiais resultantes de bioprocessos.

Por este motivo, o mercado global de produtos fermentados (excluindo biocombustíveis), que atualmente está por volta de US $\$ 24,3$ bilhões, deve crescer a uma taxa de cerca de 7,7\% ao ano até atingir o valor de US\$35,1 bilhões em $2020^{77}$. Conforme demonstrado neste texto, mesmo os mercados consolidados (aminoácidos, ácidos orgânicos, xantana) de produto "biotec" manterão seu crescimento nos próximos anos, embora um pouco abaixo desta média. Portanto, o maior crescimento 
provavelmente virá dos produtos emergentes, como alguns citados neste texto (ex.: bioaromas, biocorantes). Dentre os biocorantes, por exemplo, existem diversos processos em estágio de desenvolvimento que devem entrar neste mercado ${ }^{60}$. Portanto, os bioprocessos para produção de aditivos para a indústria de alimentos podem ser considerados ferramentas de alto potencial para a mercado que deve ganhar cada vez mais espaço no cenário econômico nos próximos anos.

\section{Referências}

1. Microbial Products. Disponível em: http://www.prnewswire.com/ news-releases/microbial-products-technologies-applications-andglobal-markets---reportlinker-review-300156939.html Acesso em: 08 Jun. 2016.

2. Gavrilescua, M.; Chistib, Y.; Biotechnol. Adv. 2005, 23, 471-499.

3. Bicas, J. L.; Maróstica, M. R.; Barros, F. F. C. C.; Molina, G.; Pastore, G. M.; Em Fermentation Processes Engineering in the Food Industry; Soccol, C. R.; Pandey, A.; Larroche, C., eds., CRC Press, 2013, 371-404, cap. 15.

4. Organic Acids Market - Global Trend \& Forecast to 2021.

5. Disponível em: http://www.morningstar.com/news/business-wire/ BWIPREM_20160608005611/global-organic-acids-marketworth-usd-929-billion-by-2021-analysis-technologies-forecastsreport-20162021-key-vendors-basf-cargill-dow-chemical-research-and-markets.html Acesso em: 08 Jun. 2016.

6. Global Amino Acids Market By 2022. Disponível em: https:// www.grandviewresearch.com/press-release/global-amino-acidsmarket. Acesso em: 08 Jun. 2016.

7. Global Market for Flavor and Fragrance. Disponível em: http:// www.bccresearch.com/pressroom/chm/global-market-for-flavorand-fragrance-to-reach-\$33.5-billion-by-2019 Acesso em: 08 Jun. 2016.

8. Global Food Colorants Market By 2020. Disponível em: https:// www.grandviewresearch.com/press-release/global-food-colorantsmarket Acesso em: 08 Jun. 2016.

9. Global Mold Inhibitors Market Report 2014-2020. Disponível em: http://www.businesswire.com/news/home/20160104006044/en/ Research-Markets-Global-Mold-Inhibitors-Propionates-Sorbates Acesso em: 08 Jun. 2016.

10. Sizing \& Thickening Agents Market - Global Trends \& Forecast to 2020 Disponível em: http://www.marketsandmarkets.com/ Market-Reports/sizing-thickening-agents-market-267603209. html. Acesso em: 08 Jun. 2016.

11. Global Vitamins Market 2014-2018. Disponível em: http://www. businesswire.com/news/home/20140217005352/en/ResearchMarkets-Global-Vitamins-Market-2014-2018-Cosmeceutical.
Acesso em: 08 Jun. 2016.

12. Vitamins - a global strategic business report. Disponível em: http://www.strategyr.com/pressMCP-2542.asp. Acesso em: 08 Jun. 2016.

13. Brazil Food Trends 2020. Disponível em: http://www.ital. sp.gov.br/tecnolat/anais/t1230513/Arquivos/Brasil\%20Food $\% 20$ Trends\%202020.pdf Acesso em: 08 Jun. 2016.

14. Global Market for Natural Food Colors. Disponível em: http:// www.beveragedaily.com/Markets/Global-market-for-naturalfood-colors-to-reach-1.7bn-by-2020 Acesso em: 08 Jun. 2016.

15. Brasil16 - Tendências de Consumo 2016 (Mintel). Disponível em: brasil.mintel.com/tendencias-de-consumo/ Acesso em: 08 Jun. 2016.

16. Bigliardi, B.; Galati, F.; Trends Food Sci. Technol. 2013, 31, 118-129.

17. Yashveer, S.; Singh, V.; Kaswan, V.; Kaushik, A.; Tokas, J.; Biotechnol. Genet. Eng. Rev. 2014, 30, 118-129.

18. Fermentation Chemicals Market. Disponível em: https://www. grandviewresearch.com/press-release/global-fermentationchemicals-market. Acesso em: 08. Jun. 2016.

19. Global Lysine Market By Application. Disponível em: https:// www.grandviewresearch.com/press-release/global-lysine-market Acesso em: 08. Jun. 2016.

20. Wendisch, V.F.; Eberhardt, D.; Herbst, M.; Jensen, J.V.K.; Biotechnological production of amino acids and nucleotides. Em Biotechnological production of natural ingredients for food industry; Bicas, J.L.; Maróstica Jr., M.R.; Pastore, G.M., eds., Bentham Science, 2016, cap. 3.

21. Sato, H.; Em Biotecnologia de Alimentos; Pastore, G.M.; Bicas, J.L.; Marostica, M.R., eds., Atheneu, 2013, cap. 10.

22. Sato, S.; Em Biotecnologia Industrial, v. III; Lima, U.A.; Aquarone, E.; Borzani, W.; Schimidell, W., eds., Edgard Blücher: São Paulo, 2001, cap. 7.

23. Sano, C.; Am. J. Clin. Nutr. 2009, 90, 728S-732S.

24. Gopinath, V.; Nampoothiri, K. M. Em Encyclopedia of Food Microbiology. 2014, 504-517.

25. Becker, J.; Wittmann, C.; Curr. Opin. Biotech. 2012, 23(4), 631640.

26. World Markets for Fermentation Ingredients. Disponível em: https://www.reportbuyer.com/product/3326183/world-marketsfor-fermentation-ingredients.html Acesso em: 08. Jun. 2016.

27. The Global Amino Acids Market: Trends, Drivers \& Projects. Disponível em: http://www.strategyr.com/MarketResearch/ Amino_Acids_Market_Trends.asp Acesso em: 08. Jun. 2016.

28. Hou, Y.; Yin, Y.; Wu, G.; Exp. Biol. Med. 2015, 240, 997-1007.

29. Feed Amino Acids Market. Disponível em: http://www. marketsandmarkets.com/PressReleases/feed-amino-acids.asp Acesso em: 08. Jun. 2016. 
30. Global Monosodium Glutamate Market. Disponível em: https:// globenewswire.com/news-release/2016/03/17/820804/0/en/ Global-Monosodium-Glutamate-Market-Poised-to-Surge-fromUSD-4-500-0-Million-in-2014-to-USD-5-850-0-Million-by-2020MarketResearchStore-Com.html Acesso em: 08. Jun. 2016.

31. Gopinath, V.; Nampoothiri, K. M.; Em Encyclopedia of Food Microbiology; Batt, C. A.; Tortorello, M-L.; eds., Elsevier, p. 513.

32. Penna, T. C. V.; Em Biotecnologia Industrial, v. III; Lima, U.A.; Aquarone, E.; Borzani, W.; Schimidell, W., eds., Edgard Blücher: São Paulo, 2001, cap. 2.

33. Citric Acid Market by Form - Global Forecast to 2020. Disponível em: http://www.marketsandmarkets.com/MarketReports/citric-acid-market-185568353.html Acesso em: 08. Jun. 2016.

34. Organic Acids Market. Disponível em: http://www. futuremarketinsights.com/reports/global-organic-acids-market Acesso em: 08. Jun. 2016.

35. Citric Acid. Disponível em: https://www.ihs.com/products/citricacid-chemical-economics-handbook.html. Acesso em: 08. Jun. 2016.

36. Kristiansen, B.; Mattey, M.; Linden, J.; Citric Acid Biotechnology. Taylor \& Francis: London, 2002.

37. Max, B. ; Salgado, J. M. ; Rodríguez, N. ; Cortés, S. ; Converti, A. ; Domínguez, J. M.; Braz. J. Microbiol. 2010, 41, 862-875.

38. Kadam, S. R. ; Patil, S. S.; Bastawde, K. B.; Khire, J. M.; Gokhale, D. V.; Process Biochem. 2006, 41, 120-126.

39. Vijayakumar, J.; Aravindan, R.; Viruthagiri, T.; Chem. Biochem. Eng. Q. 2008, 22, 245-264.

40. Lactic Acid Market by Application \& Polylactic Acid Market Global Trends \& Forecasts to 2020. Disponível em: http://www. prnewswire.com/news-releases/lactic-acid-market-by-application-polylactic-acid-market-by-application--by-geography---globaltrends--forecasts-to-2020-300257209.html Acesso em: 08 Jun. 2016

41. Lactic Acid Market worth 3.82 Billion USD \& Polylactic Acid Market worth 5.16 Billion USD by 2020. Disponível em: http:// www.marketsandmarkets.com/PressReleases/polylacticacid.asp Acesso em: 08 Jun. 2016

42. Global Lactic Acid And Poly Lactic Acid. Disponível em: https:// www.grandviewresearch.com/press-release/global-lactic-acidand-poly-lactic-acid-market Acesso em: 08 Jun. 2016

43. Flueri, L. F.; Lima, G. P. P.; Em Biotecnologia de Alimentos; Pastore, G.M.; Bicas, J.L.; Marostica, M.R., eds., Atheneu, 2013, cap. 12.

44. Lopes, B.M.; Silva, B. M.; Lessa, V. L.; Lacerda, L. G.; J. Food Nutr. Res. 2015, 54, 185-194.

45. Maugeri Filho, F.; Em Biotecnologia Industrial, v. III; Lima, U.A.; Aquarone, E.; Borzani, W.; Schimidell, W., eds., Edgard Blücher: São Paulo, 2001, cap. 6.
46. Xanthan Gum Market By Application. Disponível em: https:// www.grandviewresearch.com/press-release/global-xanthan-gummarket Acesso em: 08 Jun. 2016.

47. Wingender, J.; Neu, T. R.; Flemming, H.-C.; Em Microbial Extracellular Polymeric Substances; Wingender, J.; Neu, T. R.; Flemming, H.-C., eds., Springer, 1999, cap. 1.

48. Xanthan Gum Market By Application And Segment Forecasts To 2020. Disponível em: http://www.grandviewresearch.com/ industry-analysis/xanthan-gum-market Acesso em: 08 Jun. 2016.

49. Spector, R.; Johanson, C. E.; J. Neurochem. 2007, 103, 425-438.

50. Wildman, R. E. C.; Handbook of Nutraceuticals and Functional Foods. CRC Press: Boca Raton, 2007.

51. The Global Vitamins Market - Trends, Drivers \& Projects. Disponível em: http://www.strategyr.com/MarketResearch/ Vitamins_Market_Trends.asp Acesso em: 08 Jun. 2016.

52. Shimizu, S. Em Biotechnology Second; Rehm, H.-J., Reed, G., Puhler, A., Stadler, P., eds, Wiley-VCH: Weinheim, 2001, cap. 11, p. $320-340$.

53. Carvalho, J.C.; Ramírez, E.N.M.; Finco, A.M.O.; Mamani, L.D.G.; Magalhães, A.I.; Letti, L.A.J.; Soccol, C.R.; Vitamins and Nutraceuticals. Em Biotechnological production of natural ingredients for food industry; Bicas, J.L.; Maróstica Jr., M.R.; Pastore, G.M., eds., Bentham Science, 2016, cap. 5.

54. Berstenhorst, S.M.; Hohmann, H.-P.; Stahmann, K.-P.; Em Encyclopedia of Microbiology; Schaechter, M., eds., Elsevier, 2009, p. 549-561.

55. Bicas, J. L.; Oliveira Júnior, E. N.; Xavier, B. M.; Em Biotecnologia de Alimentos; Pastore, G.M.; Bicas, J.L.; Marostica, M.R., eds., Atheneu, 2013, cap. 13.

56. Arauz, L. J.; Jozala, A. F.; Mazzola, P. G.; Penna, T. C. V.; Trends Food Sci. Technol. 2009, 20, 146-154.

57. Jalilzadeh, A.; Tunçtürk, Y.; Hesari, J.; Int. J. Dairy Sci. 2015, 10, 44-60.

58. Kabak, B.; Var, I.; Dobson, A.; Crit. Rev. Food Sci. Nutr. 2006, 46, 593-619.

59. Zhu, Y.; Hassan, Y. I.; Watts, C.; Zhou, T.; Anim. Feed Sci. Technol. 2016, 216, 19-29.

60. Dufossé, L.; Galaup, P.; Yaron, A.; Arad, S.M.; Blanc, P.; Murthy, K.N.C.; Ravishankar, K.; Trends Food Sci. Technol. 2005, 16, 389-406.

61. Dufossé, L.; Food Technol. Biotechnol. 2006, 44, 313-321.

62. Chattopadhyay, P.; Chatterjee, S.; Sen S.K.; Afr. J. Biotechnol. 2006, 7, 2972-2985.

63. Hejazi, M. A.; de Lamarliere, C.; Rocha, J. M. S.; Vermuë, M.; Tramper, J.; Wijffels, R. H.; Biotechnol. Bioeng. 2002, 79, 29-36.

64. Long, II, T.V.; US Patent $\mathrm{N}^{\circ} 6783951.2004$.

65. Ötles, S. and Çagindi, Ö.; Em Food colorants: Chemical and functional properties. 2008, CRC Press: Boca Raton. p. 51-70. 
66. Global Carotenoids Market. Disponível em: http://www. bccresearch.com/pressroom/fod/global-carotenoids-market-reach\$1.4-billion-2018 Acesso em: 08 Jun. 2016.

67. Novakova, R.; Odnogova, Z.; Kutas, P.; Feckova, L.; Kormanec, J.; Wijffels, R. H.; Folia Microbiology. 2010, 55, 119-125.

68. Bicas, J. L.; Silva, W. S.; Número do registro de patente: BR1020130270369. 2013.

69. Spolaore, P.; Joannis-Cassan, C.; Duran, E.; Isambert, A.; Journal of J. Biosci. Bioeng. 2006, 101, 87-96.

70. Molina, G.; Bicas, J. L.; Maróstica Júnior, M. R.; Pastore, G. M.; Em Biotecnologia de Alimentos; Pastore, G.M.; Bicas, J.L.; Maróstica Júnior, M.R., eds., Atheneu, 2013, cap. 11.

71. Siegmund., B.; Em Flavour Development, Analysis and Perception in Food and Beverages; Parker, J. K.; Elmore, J. S.; Methven, L., eds., Atheneu, 2013, cap. 7, p. 127-149.

72. Europabio, 2003. Disponível em: http://www.europabio.org/sites/ default/files/facts/white_biotechnology___gateway_to_a_more sustainable_future.pdf Acesso em: 08 Jun. 2016

73. UBIC Consulting - The World Biotech Flavours Market 2014. Disponível em: http://ubic-consulting.com/wp-content/ uploads/2015/08/Biotech-Flavor.pdf Acesso em: 08 Jun. 2016.

74. Gallage, N.J., Møller, B.L.; Mol. Plant. 2015, 8, 40-57.

75. Schrader, J., Etschmann, M.M.W., Sell, D., Hilmer, J.M., Rabenhorst, J.; Biotechnol. Lett. 2004, 26, 463-472.

76. Xu, P.; Hua, D.; Ma, C.; Trends Biotechnol. 2007, 25, 571-576.

77. Vanillin Market: Global Industry Analysis. Disponível em: http:// www.futuremarketinsights.com/reports/vanillin-market Acesso em: 08 Jun. 2016.

78. World Markets for Fermentation Ingredients - Reportlinker Review. Disponível em: http://www.prnewswire.com/ news-releases/world-markets-for-fermentation-ingredients--reportlinker-review-300160023.html Acesso em: 08 Jun. 2016.

\section{Lorena O. Felipe \& Juliano L. Bicas*}

Departamento de Ciência de Alimentos, Faculdade de Engenharia de Alimentos, Universidade Estadual de Campinas. Rua Monteiro Lobato, 80, Campinas - São Paulo, Brasil.

*E-mail: jlbicas@gmail.com 